\title{
A small de novo 16q24.1 duplication in a woman with severe clinical features
}

Sylvia Quéméner-Redon ${ }^{1,2}$, Caroline Bénech ${ }^{1,3}$, Séverine Audebert-Bellanger ${ }^{4}$, Gaëlle Friocourt ${ }^{1}$, Marc Planes ${ }^{4}$, Philippe Parent $^{4}$ and Claude Férec ${ }^{1,2,3}$

${ }^{1}$ Institut National de la Santé et de la Recherche Médicale (INSERM), UMR1078, Brest, France,

${ }^{2}$ Laboratoire de Génétique Moléculaire et d'Histocompatibilité, Centre Hospitalier Universitaire (CHU), Hôpital Morvan, Brest, France,

${ }^{3}$ Etablissement Français du Sang (EFS) - Bretagne, Brest, France,

${ }^{4}$ Service de Pédiatrie et de Génétique Médicale, Centre Hospitalier Universitaire de Brest, Brest, France.

Correspondence to Pr Claude Férec, INSERM, U613 and EFS - Bretagne, 46 rue Félix Le Dantec, 29218 Brest, France; claude.ferec@univ-brest.fr 


\begin{abstract}
We report here a de novo 16q24.1 interstitial duplication in a woman with a severe phenotype consistent with mental retardation, spastic paraplegia, severe epilepsy, a narrow and arched palate, malar hypoplasia, little subcutaneous fat and arachnodactyly. Although conventional karyotyping was found to be normal, array-CGH detected a small duplication on chromosome 16. Using QFM-PCR, we characterised its proximal and distal breakpoints. The duplication, which is approximately $250 \mathrm{~kb}$, encompasses seven genes (KIAA0182, GINS2, c16orf74, COX4NB, COX4II, MIR1910 and IRF8). Several reports have previously described large 16q duplications, and some of these overlap with our region in 16q24.1.

Due to the variability of the described phenotypes, the characterisation of small $16 q$ duplications may help to determine critical regions and the genes they contain that are associated with the components of complex phenotypes.
\end{abstract}

Key words: 16q24.1, duplication, mental retardation, Array-CGH, QFM-PCR. 


\section{Introduction}

Chromosomal abnormalities are a major cause of mental retardation. Unbalanced karyotypes are estimated to be present in 10 to $16 \%$ of children with intellectual disabilities with or without dysmorphic signs and malformations $[1,2]$. The recent application of molecular karyotyping in genomic medicine has strongly improved the detection of small chromosomal defects and has revealed new information about regions that are potentially involved in intellectual disabilities [3]. Although complete trisomies of chromosome 16 are associated with spontaneous abortions, partial duplications of $16 q$ have been associated with different phenotypes such as mental retardation, dysmorphic features and limited post-natal survival [4].

Here, we report a woman with a small de novo duplication of $250 \mathrm{~kb}$ in the $16 \mathrm{q} 24.1$ region detected by chromosomal microarray and confirmed by quantitative fluorescence multiplex-PCR (QFM-PCR). Because our patient's clinical features are particularly severe considering the size of the duplication, we compared her phenotype with previously described cases of 16q trisomy [4-13]. Small chromosomal rearrangements such as the one found in this case may help to delineate the contribution of selected genes in larger 16q duplications.

\section{Clinical report}

\section{Case report}

The patient is a 26-year-old woman born to non-consanguineous and unaffected parents after an uncomplicated pregnancy. She is the second child, and her two brothers are healthy.

A marfanoid mental retardation syndrome (OMIM 248770) was suspected at 26 years old because of a 'typically' flat face and other marfanoid body habitus. Before the age of 2 years, she presented a developmental delay and dysmorphism that consisted of malar hypoplasia, a narrow and arched palate, micrognathia, long face, high forehead, anteverted nares, thick lip, large palpebral fissures, hollowed-out cheeks, arachnodactyly and little subcutaneous fat (Figure 1). An optic atrophy was also observed but not confirmed afterward. She was first treated by corticoids, but in the absence of improvement, she was treated by Rivotril. However, psychomotor difficulties were then amplified. In addition, she had an epicanthus and axial hypotonia, and her limbs were hypertonic. At 3 years old, her height was $105 \mathrm{~cm}$ (+2DS), weight was $15 \mathrm{~kg}(+1 \mathrm{DS})$ and head circumference was $48 \mathrm{~cm}$ (-1DS). At 4 years, she was able to sit alone, but she had severe communication difficulties (no language, shouting, laughing and crying without any reason). She was irritable and agitated. She 
still had a severe myopia without family history, a palpebral coloboma, and little subcutaneous fat associated with prominent muscles, in addition to joint hyperextensibility (hands, fingers and toes). At the age of 6 years, she was still unable to speak, walk, dress, eat or wash by herself. She had convulsive spasms every day. Between 7 and 12 years old, she could walk with assistance and grab objects. She had many infections and suffered from a scoliosis. At 20 years old, she was taking a combination of different sedatives. She suffered from spastic paraplegia and severe epilepsy.

A history of convulsive encephalopathy and spasms in flexion with hypsarrhythmia was shown with an electroencephalogram (EEG) analysis, and these required several hospitalisations. Other medical evaluations consisted of brain and spinal cord magnetic resonance imaging and blood amino acid and urine organic acid chromatographies, which were normal. CDG (congenital disorder of glycosylation) syndrome analysis was negative. Radiography revealed a hypertrophy at the tuft of the phalanx of the finger.

Seven years later, one of her brothers and his pregnant wife asked for genetic counselling. As no biological marker exists to confirm marfanoid mental retardation syndrome (OMIM 248770), an array-CGH was proposed to the propositi.

\section{Oligonucleotide microarray}

Chromosome analysis was performed on lymphocyte cultures using standard procedures with RHG banding.

Array-CGH analyses were performed using an Agilent Human Genome CGH microarray 105K consisting of 105,000 probes (Agilent Technologies, Santa Clara, CA). Experiments were performed with 1300 ng of DNA following the instructions provided by Agilent (Agilent Oligonucleotide Array-Based CGH for Genomic DNA Analysis, v.5.0, June 2007). Arrays were analysed using the Agilent Scanner G2505B and Feature Extraction Software version 9.5.1. Copy number variations (CNV) were obtained using the CGH Analytics software v3.5.14 (ADM-1 algorithm; moving average window: 1 Mb; cut-off: 6; 3 consecutive probes for a positive call).

\section{Array-CGH validations}

QFM-PCR was carried out as previously described to validate and refine the size of the copy number variations found by array-CGH [14]. Targeted regions in and around the CNV (sequences may be obtained 
upon request) were amplified in a single PCR using the Qiagen Multiplex PCR kit (Qiagen, Courtaboeuf, France) and analysed on an ABI Prism 310 sequencer (Applied Biosystems, Foster City, California) with Genemapper v4 (Applied Biosystems). We used one control amplicon for sample normalisation and another on the $\mathrm{X}$ chromosome. Interpretation resulted in increased or decreased fluorescence for peaks in duplicated or deleted regions, respectively.

Paternity testing was performed using the PowerPlex16® System kit following the protocol provided by Promega (Promega Corp., Madison, USA).

\section{Results}

Our patient had a normal karyotype $(46, \mathrm{XX})$ as determined by conventional methods. The $105 \mathrm{~K}$ arrayCGH experiment identified a $250 \mathrm{~kb}$ duplication in the $16 \mathrm{q} 24.1$ region, which includes 15 probes located between positions 84,263,921 and 84,500,230 bp (hg18) and encompasses seven genes (KIAA0182, GINS2, c16orf74, COX4NB, COX4I1, MIR1910 and IRF8). Other DNA gains and losses were also observed in the patient, but all of them were well-known copy number polymorphisms (CNP) (http://projects.tcag.ca/variation/). The QFM-PCR experiments, performed on the proband and her parents, showed that this duplication had arisen de novo and had refined breakpoint positions between approximately $84,246,000$ and 84,496,000 (Figure 2). No discordance was observed in the paternity testing (data not shown). In the DECIPHER database, we found three large deletions and one duplication that are responsible for various phenotypes, but no polymorphisms have been described in our region.

\section{Discussion}

Large duplications in the long arm of the chromosome $16(16 \mathrm{q} 11 \rightarrow$ qter $)$ that are not associated with other chromosomal gains or losses are very severe, causing malformations such as congenital cardiac defects, muscular hypotonia, failure to thrive and early death $[5,6]$.

Because the phenotype of our case was less severe, we looked at $16 \mathrm{q}$ duplications that were closer to our region with breakpoints located between 16q21 and 16q24.3 [7, 9, 13]. When considering duplications with 5' breakpoints located between 16q21 and 16q23, Houlston et al. [7] found similarities in patients facial features (a prominent forehead, midface hypoplasia and downward slant) and an association with intellectual disability, muscular hypotonia, congenital heart defects, failure to thrive, genitalia hypoplasia, periorbital edema, 
palpebral fissures and umbilical hernia [8-10]. Involvement of the 16q24 band causes similar characteristics, suggesting that some symptoms, such as developmental delay, cardiac defects, small palpebral fissures, periorbital edema, hypotonia, long fingers, recurrent infections, epicanthal folds broad/flat nasal bridge and high arched palate, may be related to the $16 \mathrm{q} 24 \rightarrow$ qter region $[4,11,12]$. As with many partial trisomies, 16q is associated with partial monosomy or trisomy, and the phenotypic effects of trisomy 16q may be influenced by secondary chromosome rearrangements; however, some trends tend to emerge. Table 1 summarises the most frequent clinical findings in patients with a duplicated segment of 16q.

Interestingly, three cases that were reported are phenotypically similar to our patient $[4,8,10]$. The first one was a t(16;22)(q24;q13.3) with a 22q deletion/16q duplication. The patient had a severe psychomotor/developmental delay with no speech, large nose and hyperextensibility of joints [8]. The other patients were carriers of a $\mathrm{t}(7 ; 16)(\mathrm{p} 22.3 ; \mathrm{q} 24.1)$ with a $7 \mathrm{p}$ deletion/16q duplication and a 16q23.3 $\rightarrow$ qter duplication/5p15.32 $\rightarrow$ pter deletion, respectively $[4,10]$. Among their features, they shared some characteristics with our patient: severe psychomotor retardation, hypotonia, long fingers, broad nasal bridge, high forehead, high-arched palate, epicanthal folds and malformed ears. Finally, sparse subcutaneous fat was also observed in patients with large duplications (5' breakpoints in 16q11, 16q13 or 16q21 bands), suggesting a possible involvement of the 16q24.1-qter region [7, 13]. Despite the fact that many cases have unbalanced translocations, which suggests a role for the autosomal monosomy associated with trisomy 16, these data suggest that the 16q24.1 region may contain several important genes associated with some features of the patient.

The duplicated region encompassed at least four genes that can be correlated with clinical features: IRF8, COX4NB, COX4I1 and MIR1910. IRF8 encodes "interferon regulatory factor 8." Its functions are related to the immune response, which potentially explains the recurrent infections observed in patients [15]. Loss of function mutations in the $I R F 8$ gene in mouse models are associated with susceptibility to infections and a chronic myeloid leukaemia-like syndrome [16]. Two genes belong to the cytochrome C oxidase subunit IV (COX4) family: $C O X 4 N B$ (COX4 neighbour) and COX4I1 (COX4 isoform 1). While the functions of the first gene are still unknown, the second gene appears to be implicated in different pathways. Among them, Kim et al. [17] found that the increased expression and translation of the COX4II gene may be associated with the 
lipoatrophy mechanism during antiretroviral treatment of human immunodeficiency virus (HIV) infection. This suggests a possible role for COX4II in the paucity of observed adipose tissue. Moreover, a non-synonymous $\mathrm{G}$ to A transition is associated with a reduction in cytochrome oxidase activity and could be associated with Alzheimer's disease [18]. Finally, the MIR1910 (microRNA 1910) gene encodes microRNAs that are involved in post-transcriptional regulation. This gene has not yet been implicated in intellectual disability, but the general misregulation of these small RNAs could contribute to abnormalities in brain development that are associated with psychomotor delays [19]. For example, a relationship between miRNA and DiGeorge syndrome has been suggested by Stark et al., who showed that a disruption of DGCR 8 (DiGeorge critical region) is associated with a reduction in mature miRNAs in mouse brains, which leads to a deficit in cognitive performance [20]. An understanding of the role of non-coding RNAs in brain development would be important to identify diseasecoding genes and understand the biological pathways involved in the pathogenesis of intellectual disability.

Due to the small size of the duplication presented here, this work may help to elucidate a critical region of the 16q chromosome associated with severe neurological and dysmorphic features. This duplication may cause alterations via different mechanisms: through a dosage effect of the genes located in the region, by disrupting genes at breakpoints, through a positional effect on neighbouring or distant genes and by containing regulatory elements for genes located far away on the chromosome [21] or associated with other mutation(s) in gene(s) contained in the duplication [22] or elsewhere in the genome. The effects of the duplication could also be different, as this duplication is in-tandem in the same chromosome, with a mechanism possibly mediated by repeated sequences or insertions in a different chromosomal region. However, caution must be used when attributing all of the phenotypical features noted in our patient to the duplication because this duplication may also be a novel CNV, as haploinsufficiency seems to be more common and penetrant than triplosensitivity for severe developmental phenotypes [23]. To conclude, additional reports of small duplications of this 16q24.1 band would help to refine the phenotype associated with this 16q24.1 band.

Acknowledgements The authors wish to thank the patient's family for their participation in this study. Funding This work was supported by the Fonds Européens de Développement Economique et Régional (FEDER - PRESAGE 9511) and the Direction Général de l'Offre de Soin (DHOS/OPRC/2007/35). 


\section{Legends}

Figure 1 Proband at 26 years old. [A,B] Note long face, large palpebral fissure, anteverted nares, small and attached lobe and thick lips. [C,D] Long and thin fingers and stiffness of the wrist/hand. [E,F] Talipes equinovarus deformity and stiffness of the feet.

Figure 2 Comparison of breakpoint characterisation by Array-CGH and QFM-PCR. Genomic positions are given through the hg18. 


\begin{tabular}{|c|c|c|c|c|c|c|c|c|c|c|c|c|}
\hline \multirow{3}{*}{$\begin{array}{l}\text { 16q trisomic region } \\
\text { Associated subtelomeric } \\
\text { rearrangement }\end{array}$} & \multirow{3}{*}{$\begin{array}{c}\begin{array}{c}\text { Houlson et } \\
\text { al.,1994 }\end{array} \\
16 q 22-q \text { ter } \\
15 q-\end{array}$} & \multicolumn{3}{|c|}{ Maher et al.,1991 } & \multirow{3}{*}{$\begin{array}{c}\begin{array}{c}\text { Savary et } \\
\text { al.,1991 }\end{array} \\
16 q 23-q t e r \\
\text { small 13p- }\end{array}$} & \multirow{3}{*}{$\begin{array}{l}\text { Hellani et al.,2010 } \\
\frac{16 q 23.3-q t e r}{5 p-}\end{array}$} & \multirow{2}{*}{\multicolumn{2}{|c|}{$\begin{array}{c}\text { Baker et al., } 2002 \\
\text { 16q23-qter }\end{array}$}} & \multirow{3}{*}{\begin{tabular}{|c|} 
Brisset et al.,2002 \\
$16 q 24.1-q t e r$ \\
$7 p-$
\end{tabular}} & \multirow{2}{*}{\multicolumn{2}{|c|}{$\begin{array}{l}\text { Zahn et al., } \\
2005 \\
16 q 24.1-\text { qter }\end{array}$}} & \multirow{3}{*}{$\begin{array}{c}\text { Our patient } \\
16 q 24.1\end{array}$} \\
\hline & & $16 q 21-?$ & $16 q 23-?$ & $16 q 24-?$ & & & & & & & & \\
\hline & & $10 q-$ & $3 p-$ & $22 q-$ & & & $5 q-$ & $5 q-$ & & $11 q^{-}$ & $11 q^{-}$ & \\
\hline De Novo $16 q+$ & $x$ & & & & & & & $x$ & $x$ & & & $x$ \\
\hline Intellectual disabilities & & & & $x$ & $?$ & $x$ & moderate & language & severe & $x$ & $x$ & severe \\
\hline Head circumference & $<3^{\text {rd }}$ centile & & $31 \mathrm{~cm}$ & $50^{\text {th }}$ & $32 \mathrm{~cm}$ & & $50^{\text {th }}$ & $50^{\text {th }}$ & $44.5 \mathrm{~cm}$ & & & $x$ \\
\hline Height & $25-50^{\text {th }}$ & & & & $46 \mathrm{~cm}$ & short & $10^{\text {th }}$ & $75^{\text {th }}$ & $48.5 \mathrm{~cm}$ & short & & \\
\hline Craniofacial dysmorphic features & $x$ & $x$ & $x$ & $x$ & $x$ & $x$ & $x$ & $x$ & $x$ & & & $x$ \\
\hline High forehead & $x$ & $x$ & & & $x$ & $x$ & $x$ & & $x$ & $x$ & & $x$ \\
\hline Broad nasal bridge & & $x$ & & $x$ & $x$ & $x$ & & & $x$ & $x$ & & $x$ \\
\hline Long or short philtrum & - & $x$ & & & & & & $x$ & - & $x$ & & \\
\hline Micrognathia & $x$ & $x$ & & & - & - & & & & & & \\
\hline Ears malformed & - & $x$ & $x$ & $x$ & - & $x$ & & & $x$ & - & & $x$ \\
\hline Epicanthus & & & & & & - & & $x$ & $x$ & - & & $x$ \\
\hline Palpebral fissures & $x$ & & & & $x$ & - & & $x$ & $x$ & $x$ & & \\
\hline Thin lip(s) & & & & & & $x$ & $x$ & & - & & & $x$ \\
\hline Downward slant & $x$ & & & & & & & & & & & $x$ \\
\hline Arched palate & $x$ & & & & & $x$ & & & $x$ & $x$ & & $x$ \\
\hline Other dysmorphic features & & $x$ & & & & & & $x$ & & & & $x$ \\
\hline Genitalia abnormalities & - & $x$ & & & & $x$ & & & $x$ & $x$ & & \\
\hline Fingers or feet features & $x$ & & & & $x$ & $x$ & & $x$ & $x$ & $x$ & $x$ & $x$ \\
\hline Hypotonia & - & & & & $x$ & $x$ & & & $x$ & $\mathrm{x}$ & & $x$ \\
\hline Malformations & & $x$ & $x$ & & - & $x$ & & $x$ & $x$ & $x$ & $x$ & \\
\hline Recurrent infections & & & & & & & & & & $x$ & $x$ & $x$ \\
\hline Early death & & $x$ & $x$ & & & & & & & & & \\
\hline
\end{tabular}

Table 1 Summary of the clinical features of patients with partial trisomy 16q. Clinical features are present (x) or not present (-). 


\section{REFERENCES}

[1] Van Karnebeek CD, Jansweijer MC, Leenders AG, Offringa M, Hennekam RC. Diagnostic investigations in individuals with mental retardation: a systematic literature review of their usefulness. Eur J Hum Genet. 2005; 13: 6-25.

[2] Rauch A, Hoyer J, Guth S, Zweier C, Kraus C, Becker C, Zenker M, Hüffmeier U, Thiel C, Rüschendorf F, Nürnberg P, Reis A et al. Diagnostic yield of various genetic approaches in patients with unexplained developmental delay or mental retardation. Am J Med Genet A. 2006; 140: 2063-2074.

[3] Stankiewicz P, Beaudet AL. Use of array CGH in the evaluation of dysmorphology, malformations, developmental delay, and idiopathic mental retardation. Curr Opin Genet Dev. 2007; 17: 182-192.

[4] Brisset S, Joly G, Ozilou C, Lapierre JM, Gosset P, LeLorc'h M, Raoul O, Turleau C, Vekemans M, Romana SP. Molecular characterization of partial trisomy 16q24.1-qter: Clinical report and review of the literature. Am J Med Genet. 2002; 113: 339-345.

[5] Ridler MA, McKeown JA. Trisomy 16q arising from a maternal 15p;16q translocation. J Med Genet. 1979; 16: $317-320$.

[6] Nevin NC, Coffey WW, Nevin J, Reid MM. Partial trisomy 16q in two boys resulting from a maternal translocation, $\mathrm{t}(15 ; 16)(\mathrm{p} 12 ; \mathrm{q} 11)$. Clin Genet. 1983; 24: 375-379.

[7] Houlston RS, Renshaw RM, James RS, Ironton R, Temple IK. Duplication of 16q22-->qter confirmed by fluorescence in situ hybridisation and molecular analysis. J Med Genet. 1994; 31: 884-887.

[8] Maher ER, Willatt L, Cuthbert G, Chapman C, Hodgson SV. Three cases of 16q duplication. J Med Genet. 1991; 28: 801-802.

[9] Savary JB, Vasseur F, Manouvrier S, Daudignon A, Lemaire O, Thieuleux M, Poher M, Lequien P, Deminatti MM. Trisomy $16 \mathrm{q} 23 \rightarrow \mathrm{qter}$ arising from a maternal $\mathrm{t}(13 ; 16)(\mathrm{p} 12 ; \mathrm{q} 23)$ : Case report and evidence of the reciprocal balanced maternal rearrangement by the Ag-NOR technique. Hum Genet. 1991; 88: 115-118. [10] Hellani A, Mohamed S, Al-Akoum S, Bosley TM, Abu-Amero KK. A t(5;16)(p15.32;q23.3) generating $16 q 23.3$--> qter duplication and 5p15.32 --> pter deletion in two siblings with mental retardation, dysmorphic features, and speech delay. Am J Med Genet A. 2010; 152: 1555-1560.

[11] Baker E, Hinton L, Callen DF, Altree M, Dobbie A, Eyre HJ, Sutherland GR, Thompson E, Thompson P, 
Woollatt E, Haan E. Study of 250 children with idiopathic mental retardation reveals nine cryptic and diverse subtelomeric chromosome anomalies. Am J Med Genet. 2002; 107: 285-293.

[12] Zahn S, Ehrbrecht A, Bosse K, Kalscheuer V, Propping P, Schwanitz G, Albrecht B, Engels H. Further delineation of the phenotype maps for partial trisomy 16q24 and Jacobsen syndrome by a subtle familial translocation t(11;16)(q24.2;q24.1). Am J Med Genet Part A. 2005; 139: 19-24.

[13] Rethore MO, Lafourcade J, Couturier J, Harpey JP, Hamet M, Engler R, Alcindor LG, Lejeune J. Increased activity of adenine phosphoribosyl transferase in a child trisomic for 16q22.2 to 16qter due to malsegregation of a t(16;21) (q22.2;q22;2)pat. Ann Genet. 1982; 25: 36-42.

[14] Masson E, Paliwal S, Bhaskar S, Prakash S, Scotet V, Reddy DN, Le Maréchal C, Ratan Chandak G, Chen JM, Férec C. Genetic analysis of the glycoprotein 2 gene in patients with chronic pancreatitis. Pancreas. 2010; 39: 353-358.

[15] Hambleton S, Salem S, Bustamante J, Bigley V, Boisson-Dupuis S, Azevedo J, Fortin A, Haniffa M, Ceron-Gutierrez L, Bacon CM, Menon G, Trouillet C et al. IRF8 Mutations and Human Dendritic-Cell Immunodeficiency. N Engl J Med. 2011; 365: 127-138.

[16] Turcotte K, Gauthier S, Tuite A, Mullick A, Malo D, Gros P. A mutation in the Icsbp1 gene causes susceptibility to infection and a chronic myeloid leukemia-like syndrome in BXH-2 mice. J Exp Med. 2005; 201: 881-890.

[17] Kim MJ, Jardel C, Barthélémy C, Jan V, Bastard JP, Fillaut-Chapin S, Houry S, Capeau J, Lombès A. Mitochondrial DNA content, an inaccurate biomarker of mitochondrial alteration in human immunodeficiency virus-related lipodystrophy. Antimicrob Agents Chemother. 2008; 52: 1670-1676.

[18] Lu J, Wang K, Rodova M, Esteves R, Berry D, Crafter A, Barrett M, Cardoso SM, Onyango I, Parker WD, Fontes J, Burns JM et al. Polymorphic variation in cytochrome oxidase subunit genes. J Alzheimers Dis. 2012; 21: 141-154.

[19] Provost P. MicroRNAs as a molecular basis for mental retardation, Alzheimer's and prion diseases. Brain Res. 2010; 1338: 58-66. 
[20] Stark KL, Xu B, Bagchi A, Lai WS, Liu H, Hsu R, Wan X, Pavlidis P, Mills AA, Karayiorgou M, Gogos JA. Altered brain microRNA biogenesis contributes to phenotypic deficits in a 22q11-deletion mouse model. Nat Genet. 2008; 40: 751-760.

[21] Benko S, Fantes JA, Amiel J, Kleinjan DJ, Thomas S, Ramsay J, Jamshidi N, Essafi A, Heaney S, Gordon CT, McBride D, Golzio C et al. Highly conserved non-coding elements on either side of SOX9 associated with Pierre Robin sequence. Nat Genet. 2009; 41: 359-364.

[22] Masson E, Le Maréchal C, Delcenserie R, Chen JM, Férec C. Hereditary pancreatitis caused by a double gain-of-function trypsinogen mutation. Hum Genet. 2008; 123: 521-529.

[23] Cooper GM, Coe BP, Girirajan S, Rosenfeld JA, Vu TH, Baker C, Williams C, Stalker H, Hamid R, Hannig V, Abdel-Hamid H, Bader P et al. A copy number variation morbidity map of developmental delay. Nat Genet. 2011; 43: 838-846. 